
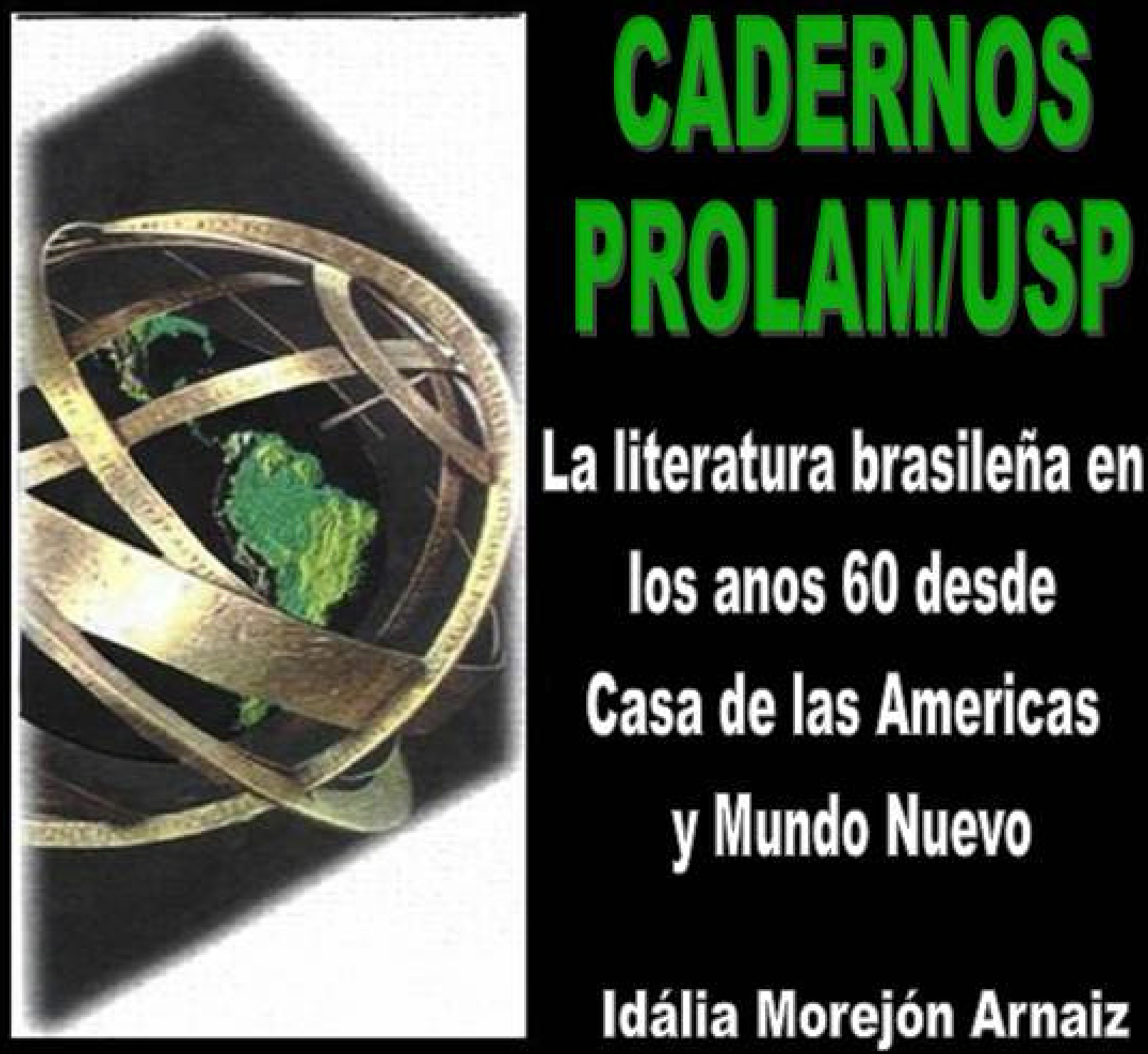

PROGRAMA DE PÓS-GRADUAÇÃO EM INTEGRAÇÃO (?) DA AMÉRICA LATINA UNIVERSIDADE DE SÃO PAULO 


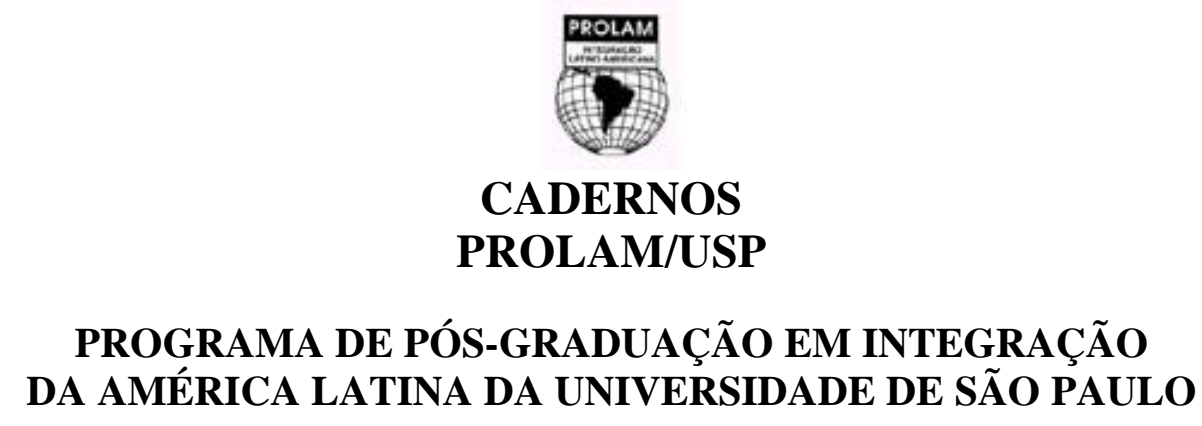

\section{TSP Universidade de São Paulo}

Reitor: Prof. Dr. Adolpho José Melfi

Vice-Reitor: Prof. Dr. Hélio Nogueira da Cruz

Pró-Reitora de Pós-Graduação: Profa. Dra. Suely Vilela

Pró-Reitor de Cultura e Extensão Universitária: Prof. Dr. Adilson Avansi de Abreu

Pró-Reitor de Pesquisa: Prof. Dr. Luiz Nunes de Oliveira

Pró-Reitora de Graduação: Profa. Dra. Sonia Teresinha de Sousa Penin

Presidente do PROLAM/USP: Profa. Dra. Maria Cristina Cacciamali

Vice-Presidente do PROLAM/USP: Profa. Dra. Cremilda Medina

Comissão de Pós-Graduação do PROLAM/USP:

Presidente: Profa. Dra. Maria Cristina Cacciamali

Vice-Presidente: Profa. Dra. Cremilda Medina

Prof. Dr. Afrânio Mendes Catani

Profa. Dra. Maria Lúcia Refinetti Martins

Prof. Dr. Osvaldo Luis Angel Cogiolla

Prof. Dr. Paulo Borba Casella

Representante Discente: José Carlos R. De Andrade

CADERNOS PROLAM/USP - Cadernos do Programa de Pós-Graduação em Integração da América Latina da Universidade de São Paulo - PROLAM/USP. Editores: Prof. Dra. Maria Cristina Cacciamali., Prof. Dr. Márcio Bobik Braga Vol. 2 (Jan./Dez. 2003) - São Paulo.

Bimestral

ISSN 1676-6288

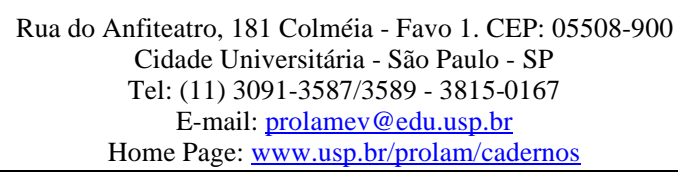




\section{CONSELHO EDITORIAL}

\section{Presidente do Conselho Editorial}

Prof. Dr. Sedi Hirano (FFLCH/PROLAM/USP)

E-mail: sedihi@usp.br

\section{MEMBROS DO CONSELHO EDITORIAL}

Adalberto Santana (UNAM/ México)

Afrânio Mendes Catani (FE/USP)

Amália Inês Geraiges de Lemos (FFLCH/USP)

Aníbal Quijano (CEIS/Peru)

Anita Kon (PUC/SP)

Carlos Antonio Romero Méndez (UCV/Venezuela)

Catalina Banko (UCV/ Venezuela)

Cremilda Celeste de Araújo Medina (ECA/USP)

Dilma de Melo Silva (ECA/USP)

Gustavo Arce (RAU/Uruguai)

Irlemar Chiampi (FFLCH/USP)

José Augusto Guilhom Albuquerque (FFLCH/USP)

Juan Carlos Campbell Esquivel (UCV/Chile)

Lisbeth Rebollo Golçalves (ECA/USP)

Lúcia Emília Nuevo Barreto Bruno (FE/USP)
Luis Felipe Cabrales Barajas (UCSHUG/México)

Luís Maurício Cuervo (UNIANDES/Colômbia)

Maria Cristina Cacciamali (FEA/USP)

Maria Lúcia Refinetti Martins (FAU/USP)

Márcio Bobik Braga (FEA/USP-RP)

Margarida Maria Krohling Künsch (ECA/USP)

Osvaldo Luis Angel Coggiola (FFLCH/USP)

Paulo Borba Casella (FD/USP)

Rafael Campos Sanchez (UNAM/México)

Raúl Bernal-Meza (UNCPBA/Argentina)

Renato da Silva Queiroz (FFLCH/USP)

Ricardo Antunes (IFCH/UNICAMP)

Sandra Maria Zakia Lian Sousa (FE/USP)

Sedi Hirano (FFLCH/USP)

Sueli Teresina Ramos Schiffer (FAU/USP)

\section{Editores}

Profa. Dra. Maria Cristina Cacciamali

E-mail:cciamali@uol.com.br

Prof. Dr. Márcio Bobik Braga

E-mail: marbobik@usp.br

\section{Capa, Diagramação e Editoração}

Renata Alves Ribeiro

E-mail: prolamev@edu.usp.br 


\section{OBJETIVOS}

O CADERNOS PROLAM/USP é uma publicação periódica bimestral, indexada, com Conselho Editorial de Arbitragem. O eixo temático é a integração da América Latina analisado sob quaisquer das seguintes dimensões: social, econômica, política, relações internacionais e cultural. Todos os trabalhos são submetidos ao Conselho Editorial e avaliados por pareceristas, não havendo identificação do(s) autor(es). 


\section{NORMAS EDITORIAIS}

Cada número do CADERNOS PROLAM/USP será composto por um ensaio ou conjunto de artigos, contendo no máximo 25 páginas. $\mathrm{O}$ padrão é: letra Times New Roman; espaço 1,5; notas colocadas no rodapé de cada página; simples referência de autoria colocada entre parênteses no próprio texto; referências da bibliografia efetivamente citada ao longo do artigo listadas no final do texto, de acordo com a norma NBR-6023 da ABNT Internacional. $\mathrm{O}$ autor deverá fornecer disquete do texto em WORD 6.0, nos formatos RTF ou DOC. Caso o artigo apresente tabelas e gráficos, o autor também deverá fornecer disquete dos mesmos nos formatos XLS ou RTF. Mapas deverão ser entregues nos formatos originais e separados do texto. Os idiomas da publicação são: português, espanhol, inglês ou francês. 


\title{
La literatura brasileña en los años 60 desde Casa de las Américas y Mundo Nuevo
}

\author{
Idalia Morejón Arnaiz ${ }^{1}$
}

\begin{abstract}
Resumen:
A través del recorte de las letras brasileñas realizado por las revistas Casa de las Américas (1960-1971) y Mundo Nuevo (1966-1971), este artículo realiza una lectura de los ejes ideoestéticos que presidieron los discursos críticos sobre dicha literatura en el ámbito hispanoamericano de los años sesenta.
\end{abstract}

Palabras-clave: Literatura brasileña, Revista Mundo Nuevo, Emir Rodríguez Monegal

\section{Resumo:}

Através do recorte das letras brasileiras realizado pelas revistas Casa de las Américas (1960-1971) e Mundo Nuevo (1966-1971), este artigo tenta uma leitura dos eixos ideo-estéticos que presidiram os discursos sobre essa literatura no âmbito hispano-americano dos anos sessenta.

Palabras-clave: Literatura brasileira, Revista Mundo Nuevo, Emir Rodríguez Monegal

\footnotetext{
${ }^{1}$ Doutoranda do Programa de Pós-graduação em Integração da América Latina - PROLAM/USP
} 


\section{Casa de las Américas (1960-1971) ${ }^{2}$}

Cuando en 1960 se funda en La Habana la revista Casa de las Américas, su primer editorial expresa el objetivo de alcanzar la unidad cultural y política inspirada en el ejemplo reciente de la revolución cubana. La creencia en una "concepción de la vida hispanoamericana" ${ }^{3}$ indicaba que la lengua española sería el eje que estructuraría tal posibilidad. El propio título de la revista sugería que Cuba sería, a partir de aquel momento, el hogar de la literatura del continente. Sin embargo, desde el punto de vista lingüístico, Brasil era excluido.

Así, la travesía de la literatura brasileña por las páginas de Casa de las Américas se integra a un recorte desequilibrado y azaroso, mediado por el discurso ideológico de la revolución. Su presencia no fue ni sistemática ni totalmente representativa; los autores y obras promovidos aparecen en función de construir una estética literaria en consonancia con la política institucional de la revolución. La nueva novela trataba entonces de superar las limitaciones del estilo regionalista en función del cosmopolitismo y de la universalidad, como manera de reivindicar el lugar central de América Latina con relación a Occidente.

Sin embargo, en su lectura Casa de las Américas se mantuvo alejada de esta perspectiva moderna, ya que su mayor prioridad era la configuración de un mapa literario que legitimase los objetivos políticos de la revolución -básicamente, su exportación a otros países. Así, el recorte brasileño privilegia la novela regionalista de temática social, con el objetivo de mostrar la injusticia y la miseria existente en los países latinoamericanos.

Vidas Secas, de Graciliano Ramos, es publicada en 1964 por la editorial de Casa de las Américas, y reseñada ese mismo año en el número 26 de la revista ${ }^{4}$. El autor de la reseña es Jorge Timossi, quien utiliza informaciones periodísticas sobre la gravedad de la crisis agraria en el estado de Pernambuco inmediatamente después del golpe de estado de 1964, para mostrar que la ficcionalidad de Ramos se corresponde con una realidad agreste y desoladora, en la cual las adversidades de la naturaleza se mezclan con la violencia y la injusticia, formando uno de los cuadros más tristes de la miseria en Brasil. De ese modo, la motivación

\footnotetext{
${ }^{2}$ El año 1971 ha sido tomado como fecha que clausura muchos de los debates ideoestéticos desarrollados en América Latina durante la década del sesenta, pero no coincide con la desaparición de esta revista, que ya cuenta con 44 años de existencia.

3 “Como haremos”. Casa de las Américas, La Habana, n. 1, jul, 1960, p. 3.

${ }^{4}$ Jorge Timossi, “Graciliano Ramos. Vidas Secas". Casa de las Américas, La Habana, a. 4, n. 26, oct-nov, 1964, pp. $165-167$.
} 
ideológica para la edición cubana se basa en considerar Vidas Secas como "una de las novelas más representativas de este increíble estado de deshumanización, de alienación, literatura social y política que desde los años 30 configura la «novela del nordeste»” (p. 165).

El tono de la reseña destaca el lado hosco y difícil de la vida de los personajes, mientras que reivindica la validez del estilo realista para el tratamiento de la temática de la tierra. La estructura lineal es exaltada, por la manera "descarnada" y transparente en que presenta el contenido de los capítulos. En 1964, cuando la novela brasileña se renovaba en los libros de Clarice Lispector o Guimarães Rosa, Timossi afirma que Vidas Secas "abre una serie de perspectivas a la narrativa brasileña" (p. 167), llegando inclusive a polemizar con una zona de la crítica brasileña, que veía la novela del nordeste como una etapa finalizada en la década del cuarenta. Así, el peso y la presencia de esta novela en Casa de las Américas no está relacionado únicamente con el interés de dar a conocer una zona de la literatura brasileña, sino también con la necesidad de poner en recirculación una estética legitimadora del proyecto revolucionario.

Curiosamente, esta reseña aparece en un número de la revista hoy considerado antológico, ya que fue el punto de partida para la construcción y propagación del Boom de la novela latinoamericana. Organizado por Ángel Rama, incluía fragmentos de las obras de Julio Cortázar, Juan Carlos Onetti, Carlos Fuentes, Alejo Carpentier, Ernesto Sábato y Mario Vargas Llosa. En el ensayo "Diez problemas para el novelista latinoamericano" que abría ese número, Rama presentaba y analizaba la nueva literatura continental. El eje hispanoamericano, sin embargo, continuaba siendo el mismo: la moderna literatura brasileña no aparecía en la selección. Aun así, Rama la destaca como "una de las más diferenciables, autónomas, «nacionales», que haya dado el continente ${ }^{5 "}$ (p. 14).

A diferencia del reseñista de Vidas Secas, Rama se limita a reconocer en Graciliano Ramos apenas al maestro de la novela que pertenece a un momento anterior de la historia literaria de Brasil. Ahora se trata de una obra "monumental", Grande Sertão: Veredas, que contrasta justamente con el estilo de Graciliano "por su sabiduría lingüística y su operación de revitalización del habla popular, ascendida a estructuras cultas" (p. 14). Esto es, el crítico uruguayo suscribe como valor la estructura universal del lenguaje ligada a la herencia de las vanguardias europeas de la década del veinte, mientras que la voz institucional representada por Timossi promueve el enfoque sociopolítico, también como valor.

\footnotetext{
${ }^{5}$ Sería interesante investigar por qué Rama no incluye textos brasileños en dicho número.
} 


\title{
1.1. Machado de Assis, Drummond de Andrade.
}

Paralelamente al énfasis dado a la crítica social, otros autores brasileños son presentados como figuras aisladas, singulares, dentro de la historia de las letras brasileñas. Joaquim Maria Machado de Assis y Carlos Drummond de Andrade representan otra tendencia de la revista, en la que el interés institucional y el personal de Arrufat se cruzan. En 1963 la editorial de Casa había publicado las Memorias póstumas de Blas Cubas, y al año siguiente, justamente en el número que sigue a la reseña sobre Vidas Secas, la revista publica un extenso artículo sobre Machado de Assis. ${ }^{6}$ Con el mismo se inicia la edición número 27, y dentro de la sintaxis del la revista ocupa un espacio central, en el que el prestigio literario de Machado se combina con el prestigio local del autor del artículo, José Rodríguez Feo. Fundador de Orígenes en la década del cuarenta, disidente de la misma a finales de los cincuenta y enseguida fundador de Ciclón, Rodríguez Feo escribe un texto panorámico sobre el autor de Quincas Borba y Don Casmurro, que no es precisamente una reseña de la edición cubana de las Memorias. ${ }^{7}$ El interés consiste en mostrar al lector la vida y la obra de Machado de Assis, y comentar algunas de sus líneas estilísticas y temáticas más notables: la lucha entre razón y locura, el materialismo como expresión de la indiferencia, el tedio, el vacío de la vida; en otras palabras, la visión pesimista de la vida que tenía el novelista brasileño, y la manera en que muestra las contradicciones entre su personalidad y su éxito como hombre público.

Pero el aspecto interesante que revela este artículo es la lectura social de los personajes -Blas, Bentiño, Rubiao- hecha específicamente para rectificar el consenso de los críticos respecto a la indiferencia de Machado ante los conflictos sociales y políticos de su época:

\begin{abstract}
Si me detengo en estas consideraciones, se debe a que confirman mi sospecha de que los críticos se han equivocado al presentar a Machado como un hombre aislado de los conflictos políticos y sociales de su época [...] Que Machado no se ocupase en sus romances de temas políticos es una cosa, y otra, que no estuviese consciente de estos problemas [...] Los temas que trata en su obra [...] tienen una raíz social que él comprendió muy bien. (p. 18)
\end{abstract}

Según la visión de Rodríguez Feo, aun cuando la obra no denuncie o reflexione sobre las contradicciones sociales o de clase, el autor, como individuo, salva el escollo ideológico. Sus palabras sirven para constatar cuáles son los valores que la política cultural de la revista erigió en parámetros de legitimación literaria. Este enfoque aparece también como un espacio

\footnotetext{
${ }^{6}$ José Rodríguez Feo, “Machado de Assis”. Casa de las Américas, La Habana, a. 4, n. 27, dic., 1964, pp. 12-20.

${ }^{7}$ Joaquim Maria Machado de Assis, Memorias póstumas de Blas Cubas. La Habana, Casa de las Américas, 1963. Ya en 1951 la editorial mexicana Fondo de Cultura Económica había traducido y publicado esta novela.
} 
de transacción ideológica, como una lectura que, a diferencia de las que según el cubano habían sido hechas por otros críticos, encuentra en la obra literaria elementos que provienen no del contexto en que fue escrita, sino del contexto en que estaba siendo leída.

Una segunda lectura panorámica aparece en este año de 1964. El número 25 publica una presentación de la poesía de Carlos Drummond de Andrade $^{8}$, abundante en citas, acompañada de una selección bien nutrida de poemas pertenecientes a los libros más conocidos de Drummond, como Alguma Poesia, A Rosa do Povo, Novos Poemas, Claro Enigma y A vida passada a limpo. Lo que se destaca es el estilo, herencia del modernismo brasileño y de la poesía de lengua inglesa, mas las particularidades de su propio lenguaje. Los textos publicados son presentados como el testimonio de la más alta poesía universal, colocando a Drummond en la calidad de precursor. Del poeta minero "parten", dice nuevamente Timossi, "varios de los caminos de los que se nutre la poesía que todos sentimos como nuestra” (p. 61).

Aunque muchos de los poemas publicados muestren la preocupación de Drummond por toda la humanidad, su belleza, ayudan a disfrutar de los textos libres del compromiso 9 .

\subsection{4: un año diferente}

Al revisar las estadísticas del Premio Casa de las Américas se percibe que durante su primera década de existencia, la participación de escritores brasileños es prácticamente nula. El aislamiento lingüístico y político confirman la hipótesis del desequilibrio azaroso de este proyecto de unidad continental. Por primera vez, una obra brasileña es premiada ${ }^{10}$. Oduvaldo Viana Filho vence por unanimidad del jurado, en el género teatro, con una obra titulada Cuatro cuadras de tierra ${ }^{11}$.

Casa de las Américas tenía como política editorial reseñar o publicar fragmentos de obras ganadoras en el concurso literario, y es Antón Arrufat, dramaturgo y entonces director

\footnotetext{
${ }^{8}$ Jorge Timossi, "Carlos Drummond de Andrade”. Casa de las Américas, La Habana, a. 4, jul-ago, 1964, pp. 6173; Carlos Drummond de Andrade, "Poemas", ed. cit., pp. 74-81. Poemas seleccionados: "El sobreviviente", "Aurora", "Muerte en el avión", "Noticias de España", "Estrambote melancólico", "La vida pasada en limpio".

${ }^{9} \mathrm{Mi}$ perspectiva, por otro lado, enfatiza lo ideológico, pues lo que me interesa es detectar la contaminación del discurso estético con el discurso de la crítica social.

${ }^{10}$ Existe el registro de una obra enviada al concurso en 1961, pero como no recibió ningún premio, no se consigna el género, ni el autor. Cfr. Inés Casañas y Jorge Fornet, Premio Casa de las Américas. Memoria. La Habana, Fondo Editorial Casa de las Américas, 1999.

${ }^{11}$ El jurado estaba integrado por: Isidora Aguirre (Chile), Atahualpa del Cioppo (Uruguai), Vicente Revuelta (Cuba) e Alejandro Verbitsky (Argentina).
} 
de la revista, quien escribe una breve nota crítica sobre el texto ganador. La brevedad de la nota, así como la manera concisa en que comenta los logros y desaciertos de Cuatro cuadras de tierra, reflejan su falta de entusiasmo, su escepticismo en cuanto a la trascendencia de la temática rural. En Brasil, la discusión acerca de la reforma agraria y de las contradicciones entre la modernización de la burguesía industrial y el conservadurismo de los grandes latifundistas, le conferían a tal temática un significado que dentro del contexto cubano había perdido actualidad. La reforma agraria era un hecho consumado, y el teatro cubano, que durante años había padecido el lenguaje panfletario de denuncia social, se encontraba entonces en una línea de renovación vanguardista. La denuncia social a través de la tragedia agraria era para Arrufat, que mal conseguía acompañar la política institucional de la revista, una regresión en el desarrollo del teatro.

Así, la obra premiada no es reconocida por la revista de la institución que le dio el premio, siendo evidente que la política de los premios estaba destinada a reconocer obras que denunciasen la situación del campesino en América Latina, las injusticias de los hacendados, y la necesidad de revertir esa situación. La literatura de combate pasa a ocupar entonces un lugar predominante dentro de lo que sería llamado "poética revolucionaria", principalmente por los críticos el predominio de los valores estéticos sobre los políticos ${ }^{12}$. Aun así, Arrufat reconoce como logros de Cuatro cuadras de tierra, la ausencia de una "retórica tribunicia", la concepción psicológica del protagonista, y el conflicto de la incomunicación humana, que se hace patente entre dos clases sociales, la del campesino y la del latifundista. Esta obra es la única brasileña premiada en los primeros cinco años de existencia del concurso, y hasta entonces la segunda participante. Si consiguió arrancar el voto unánime del jurado, esto se debe, ante todo, al interés político en mostrar para todo el continente que la función primera de la literatura y del arte en general es la de servir a la lucha de los pueblos por su liberación.

A partir de 1964 y hasta 1971, el año en que encierra todo un ciclo de pequeñas libertades y grandes contradicciones dentro de la revolución cubana, las pocas noticias y colaboraciones brasileñas que aparecen siguen el camino de la denuncia. La sección "Al pie de la letra" acompaña el éxito de las traducciones de Jorge Amado ${ }^{13}$; las declaraciones de los

12 Cfr. Emir Rodríguez Monegal, "Literatura y Revolución en las letras cubanas". Revista Iberoamericana. Pittsburg. v. xli, n. 92-93, jul-dic, 1975.

${ }^{13}$ Breve noticia sobre la traducción al inglés de la novela de Jorge Amado, A morte e a morte de Quincas Berro d’Água. "Al pie de la letra”. Casa de las Américas, La Habana, a. 6, n. 34, ene-feb, 1966, p. 144. 
jóvenes intelectuales de izquierda ${ }^{14}$; la postura antiimperialista y a favor de la lucha armada de Antonio Callado. ${ }^{15}$ También, poetas como Vinícius de Moraes $^{16}$ y Thiago de Mello ${ }^{17}$ contribuyeron de forma esporádica, aunque valiosa, a la divulgación de la producción poética brasileña del momento.

Se sabe además que 1964, el año en que Brasil entra el difícil período de la dictadura militar, canceló las posibilidades de integración con Cuba. Una buena parte del silencio y de las insuficiencias del recorte literario hecho por Casa de las Américas provienen de esta circunstancia $^{18}$. Pero de cualquier manera, la estética reivindicada era la del estímulo a la crítica social y a la producción de una literatura de combate que legitimase el proyecto ideológico de la revolución.

\section{Mundo Nuevo (1966-1971)}

Mundo Nuevo fue una revista cultural que surgió en 1966 y hasta agosto de 1968 fue editada en Paris; a partir de esa fecha fue publicada en Buenos Aires. Durante la etapa

\footnotetext{
${ }^{14}$ Reseña sobre el número 257 de la revista Les Temps Modernes (out. 1967) dedicada al Brasil. Número organizado por Celso Furtado, con colaboraciones de Helio Jaguaribe, Francisco C. Weffort, Fernando Henrique Cardoso, Florestan Fernandes, J. Leite Lopes, Otto-Maria Carpeaux, Antonio Callado y Jean-Claude Bernardet. "Tiempos modernos brasileños". "Al pie de la letra". Casa de las Américas, La Habana, a. 8, n. 48, mayo-jun, 1968 , p. 154.

15 “Callado habla desde Hanói”. Al pie de la letra. Casa de las Américas, La Habana, a. 9, n. 51-2, nov 1968- feb 1969, pp. 265-6. Callado visitó Cuba en 1978, como miembro del jurado del concurso literario Casa de las Américas, en la categoría cuento.

${ }^{16}$ Vinícius de Moraes, "Retrato de mujer”. Casa de las Américas, La Habana, a. 10, n. 58, ene-feb, 1970, p. 767.

${ }^{17}$ Thiago de Melo, "Meditación en el Reino de la Pantera Azul". Casa de las Américas, La Habana, a. 7, n. 42, mayo-jun, 1967, pp. 100-1. Este poema fue leído por su autor en el Encuentro con Rubén Darío, celebrado en el balneario de Varadero, entre el 16 y el 22 de enero de 1967. Los poemas leídos en el encuentro fueron recopilados por la revista en el número 42, dedicado a homenajear al gran poeta del modernismo hispanoamericano. El poema de Thiago de Melo, desde el título anuncia su homenaje a Darío y al cuaderno Azul. La pantera evoca la sensualidad y la elegancia del lenguaje dariano, pero al mismo tiempo su riesgo. El poema de De Melo es un homenaje, también, a la influencia Del modernismo hispanoamericano sobre la poesía de todo el continente: "Y en su reinado luminoso clavas/ estas huecas raíces de silencio/ que se hunden cantando por la tierra". (p. 101)

${ }^{18} \mathrm{~A}$ pesar del aislamiento político y lingüístico que mantuvo a Brasil al margen de la política latinoamericanista presidida por la revolución cubana, cabe señalar que en el mismo año del triunfo guerrillero (1959), Fidel Castro realizó una gira internacional que incluyó, además de los Estados Unidos y Canadá, Argentina, Brasil y Uruguay; el 14 de noviembre de 1961 México y Brasil rechazaron la moción contra Cuba presentada en la Organización de Estados Americanos. También, en 1963 se celebró en Brasil un Congreso Continental de Solidaridad con Cuba. Estos datos han sido extraídos de una cronología de los hechos más importantes de la revolución preparada por la Editora Política del Departamento de Orientación Revolucionaria del Comité Central del Partido Comunista de Cuba. Entre el año 1963 y 1969, fecha esta última en que se registra la llegada a La Habana de los revolucionarios brasileños que fueron canjeados por el embajador norteamericano en Brasil, no se registra ninguna otra información. En: Cronología: 25 años de Revolución. La Habana: Editora Política, 1987.
} 
parisina (1966-1968) fue dirigida por Emir Rodríguez Monegal, y posteriormente por el sociólogo argentino Horacio Daniel Rodríguez, hasta 1971 cuando dejó de ser editada. Bajo la dirección del primero, la revista fue dinámica y animada, y su mayor prioridad en esos años fue la celebración de la nueva narrativa latinoamericana, que se vio estimulada en su crecimiento y analizada críticamente de manera tal que pudiese ser recibida como un producto no legitimado por la temporalidad, esto es, por primera vez la consagración de las obras del llamado boom de la novela latinoamericana no es presentado desde una perspectiva historicista, según la cual las obras adquieren cierto valor después de pasado algún tiempo. Rodríguez Monegal lee la literatura del momento y la pone a circular dentro de su propia dinámica. El segundo número (agosto de 1966) es notable por incluir un capítulo inédito de Cien años de soledad, del colombiano Gabriel García Márquez. En sus primeros números también aparecieron capítulos de nuevas novelas de Carlos Fuentes, Manuel Puig, Guillermo Cabrera Infante y Severo Sarduy.

En la "Presentación" del primer número, la revista declara sus creencias y aspiraciones, ofreciendo al lector una especie de manifiesto:

\begin{abstract}
El propósito de Mundo Nuevo es insertar la cultura latinoamericana en un contexto que sea a la vez internacional, que permita escuchar las voces casi siempre inaudibles de todo un continente y que establezca un diálogo que sobrepase las conocidas limitaciones de nacionalismos, partidos políticos (nacionales o internacionales), capillas más o menos literarias y artísticas. Mundo Nuevo no se someterá a las reglas de un juego anacrónico que ha pretendido reducir toda la cultura latinoamericana a la oposición de bandos inconciliables y que ha impedido la fecunda circulación de las ideas y puntos de vista contrarios.
\end{abstract}

Por eso, el lugar de la enunciación se localiza como imagen desterritorializada de la gran familia literaria latinoamericana, en una ex capital literaria reciclada con el ingreso de los jóvenes escritores latinoamericanos al mercado internacional de bienes y símbolos, por el sentimiento de estar inmerso en una cultura más amplia, fuera de lo que Rodríguez Monegal llamaba "los cotos"; un espacio, en suma, que permitía a "los exiliados voluntarios" despojarse de sus respectivos provincianismos con relación a las metrópolis. Era una forma de romper conscientemente con los tradicionalismos para comunicarse en el lenguaje internacional de una cultura paranacional. En la metrópolis europea, Mundo Nuevo y sus colaboradores encuentran condiciones favorables para autolegitimarse como grupo divergente de la norma latinoamericana del compromiso revolucionario, y de la cual la cubana Casa de las Américas se constituiría como líder. Está latente en Mundo Nuevo la idea de que la literatura latinoamericana, como en otro momento sucedió con la norteamericana, se 
construye desde afuera: "hay un momento en que una literatura existe y va adelante gracias a sus emigrados"19 , afirma Carlos Fuentes en el primer número de la revista. Para él, la visión totalizadora de la literatura proviene de la vivencia en espacios que contrastan con las realidades locales. También, el clima de renovación filosófica que precedió a Mayo del 68 de modos diversos se constituyó como síntoma de un mismo fenómeno cultural, como "un resurgimiento del humanismo", de defensa del hombre contra el "sistema", como "futuro del izquierdismo".

No se debe olvidar que Mundo Nuevo obtuvo, más allá de sus incuestionables valores literarios, una recepción negativa por la filiación política liberal de sus directores y por la fuente que la financiaba: el ILARI (Instituto Latinoamericano de Relaciones Internacionales) directamente conectado a la Fundación Ford y al Congreso por la Libertad de la Cultura, órgano financiado por la CIA. Ya desde los años 50, en pleno auge de la Guerra Fría, el Congreso era el encargado de contrarrestar la enorme influencia conseguida por los intelectuales de izquierda dentro de la sociedad después de la Segunda Guerra Mundial, cuando la idea del compromiso político comienza a ramificarse en diversas variantes entre los grupos de escritores y artistas de América.

Para la América Hispánica, la antecesora de Mundo Nuevo fue Cuadernos; para Brasil existió Cadernos Brasileiros, dirigida por el profesor Afrânio Coutinho. El hecho de tratarse de revistas institucionales respaldadas por el Congreso por la Libertad de la Cultura, organización fundada en 1950 con el objetivo de insertar el debate sobre la libertad individual del escritor en el contexto de la Guerra Fría, les garantizaba cierta estabilidad financiera, así como espacios de circulación y periodicidad estables. Súmesele a esto otro hecho: el constante apelo a firmas autorizadas para tratar de asuntos literarios, sociológicos, artísticos o políticos.

Uno de los aportes que Mundo Nuevo trae a la literatura latinoamericana es su interés por lo continental. Desde el propio título esta publicación se amplifica, se abre al continente, contrario a las imágenes locales de revistas como Sur (Buenos Aires, 1931-1970) u Orígenes (La Habana, 1944-1956), que se centraron en el valor de construcción de lo nacional, aunque sin comprometer su identificación con lo foráneo. Fue esa perspectiva continental la que le permitió a la revista, desde sus propósitos iniciales, pensar en la literatura del continente fuera del parámetro de la lengua, que le confería hegemonía a los países hispanoamericanos.

\footnotetext{
${ }^{19}$ Carlos Fuentes, "Situación del escritor en América Latina" (entrevista de Emir Rodríguez Monegal). Mundo
} Nuevo. Paris, n. 1, jul, 1966, p. 8. 
Rodríguez Monegal, al ver la literatura del momento como un fenómeno de lenguaje "internacional", es uno de los primeros críticos latinoamericanos que desde su revista acompaña y participa en la construcción de un nuevo canon literario para América Latina: el de la llamada "nueva novela" glorificada por el "boom". Devolviéndole a la frase todo lo que podría contener de trascendente, podría afirmarse que Rodríguez Monegal fue, entre otras cosas, un "descubridor de talentos", un espíritu sagaz y libre al extremo de acoger y modelar para la historia literaria de América Latina una estética narrativa capaz de desplazar la centralidad del canon europeo. Muy a pesar de los votos negativos de los intelectuales latinoamericanos revolucionarios, en Mundo Nuevo Rodríguez Monegal preserva a la literatura de la exposición constante y prolongada a las confrontaciones y polémicas ideológicas, cuyo asunto central, el compromiso revolucionario, controlaba desde el punto de vista discursivo la circulación de ideas entre América Latina, Europa y los Estados Unidos.

Veremos entonces cómo Mundo Nuevo lee la literatura del Brasil, cuáles son los discursos autorizados para dar una imagen cultural y política del mayor país de todo el continente. En primer lugar, el volumen de información que Mundo Nuevo aporta sobre Brasil sería tal vez uno de los mayores a los que en los años sesenta una revista latinoamericana tendría acceso. Aunque publicada en París, contaba con corresponsalías y distribuidoras en numerosos países de América Latina, que era el espacio a que estaba destinada. En Rio de Janeiro, la Librería Hachette era la encargada de su distribución, y probablemente algunos de sus corresponsales (cuyos nombres durante el período de Rodríguez Monegal nunca aparecen publicados) estarían vinculados a la veterana Cadernos Brasileiros $(1959-1970)^{20}$, otra de las publicaciones de la llamada "gran familia liberal". Desde que el argentino Horacio Daniel Rodríguez asume la dirección de la revista y hasta 1971, cuando deja de ser financiada por el ILARI y desaparece, sus vínculos con Cadernos Brasileiros se estrechan al punto de traducir casi íntegramente, en el número 33 de marzo de 1969, cuatro trabajos de enfoque sociohistórico sobre la esclavitud, la abolición y los problemas raciales del Brasil, anteriormente publicados en el número 47 de Cadernos Brasileiros, entre mayo y junio de 1968..$^{21}$ Diferente de Rodríguez Monegal, que era periodista, profesor y crítico literario, el

\footnotetext{
${ }^{20}$ Sobre esta revista se debe tener en consideración el análisis discursivo realizado por Kristine Vanden Berghe en Intelectuales y Anticomunismo. La revista 'Cadernos Brasileiros' (1959-1970). Leuven University Press, 1997.

${ }^{21}$ Manuel Diegues Junior, "Brasil: El cuadro social después de la abolición de la esclavitud” (p. 4-7); Trajano Quinhones, "Breve sinopsis de la abolición" (p. 8-10); Florestan Fernández, "El drama del negro y del mulato en una sociedad que cambia" (p. 11-21); Bolivar Lamounier, "Raza y clase en la política brasileña" (p. 22-29).
} 
segundo director de Mundo Nuevo tenía una formación sociológica que garantizó a los de su clase un espacio privilegiado dentro de las páginas de la revista. Si bien continuó preocupado con los asuntos de actualidad, el recorte que hace deja de ser sustancialmente literario para ocuparse de temas políticos y sociales como el militarismo, los movimientos estudiantiles, el racismo o la reforma agraria.

\section{Un recorte de recortes}

En los primeros números de la revista, la presencia brasileña está limitada a lo que desde París Rodríguez Monegal encuentra en otras publicaciones. En principio, el tipo de información sobre Brasil, más que literaria es cultural: textos críticos sobre literatura o política concentrados en las secciones de análisis de la revista, y breves reseñas o noticias sobre asuntos variados (cine, artes plásticas, teatro, dinámica editorial) agrupadas en la sección ““'Sextante”. Bajo la dirección de Horacio Daniel Rodríguez se comprobará que las novedades brasileñas siempre van firmadas por Afrânio Coutinho, principal colaborador brasileño de Mundo Nuevo, en un fraterno intercambio institucional entre las revistas del Congreso por la Libertad de la Cultura.

Rodríguez Monegal, por su parte, no revela el nombre de los que él llama corresponsales, tal vez porque las informaciones fueran obtenidas informalmente o por cartas personales, en un momento en que acatar el discurso del poder político significaba escamotear el impacto negativo que el golpe militar de 1964 había causado sobre la sociedad y la vida política brasileña. O tal vez, simplemente, porque no se tratase de notas que presentasen o valorasen los acontecimientos según el discurso de la tradición liberal. Así, reseña la Revista de Cultura Brasileña, editada en español por la Embajada de Brasil y dirigida por Ángel Crespo, la cual en el número 16 publicó la primera traducción a una lengua extranjera del poema "Cobra Norato", de Raul Bopp (MN: 1, 75). Igualmente comenta los altibajos en la calidad de la chilena Orfeo, cuyo número 15-16 está dedicado a la poesía de Brasil y recoge, en primer lugar, un homenaje a Cecilia Meireles, "para proseguir”, según palabras del propio Rodríguez Monegal, “con una escuálida muestra de poesía romántica y simbolista de aquel país y concluir con una selección un poco más nutrida de poetas que pueden considerarse

En el número anterior, la propia revista Mundo Nuevo había hecho la propaganda del número 47 de Cadernos Brasileiros. 
modernos, desde Mario de Andrade a Murilo Mendes. Las traducciones, acompañadas de sus originales, dejan bastante que desear" (MN: 2, 63). Obviamente, sus críticas no van dirigidas tanto a la poesía brasileña y sí al recorte que Orfeo hizo de la misma; sus consideraciones al respecto dejan entrever una apreciación de la poesía al mismo tiempo personal por el estilo y profesional por el lenguaje, si acaso esto es posible. Se trata de la postura crítica de quien interviene en la conformación de un corpus literario continental, con el objetivo de mostrar lo mejor y lo más actual. Al calificar la muestra de Orfeo como "escuálida”, Rodríguez Monegal apunta directamente a las fallas de la revista chilena en cuanto a su conocimiento y valoración de la poesía brasileña. Sin embargo, el crítico uruguayo no usa su revista para corregir las fallas de los recortes literarios hechos por otras publicaciones, ya que como se hace evidente, su interés está totalmente volcado hacia la promoción de los escritores y novelas del "boom".

Aun así, el interés que Rodríguez Monegal dedica a cualquier tipo de información inexacta no es menos rigurosa cuando se trata de aclarar malentendidos y afinar las visiones distorsionadas que de la América Latina tienen algunas publicaciones. En general, las secciones "Revistas” y “"Sextante”” están dedicadas a ajustar las ópticas que se desvían hacia los extremos, ya sean éstos ideológicos o de pura ignorancia en el plano cultural. En un párrafo contundente y bien humorado, Rodríguez Monegal critica la ignorancia y la falta de profesionalismo de Le Nouvel Observateur, que en su número 69 dedica un artículo a las ligas campesinas en el Nordeste del Brasil afirmando lo siguiente: "Como el Padre Lage, tampoco Julião es de origen popular. Este nieto de latifundistas ha estudiado derecho. Tiene la pasión de escribir, y se le deben algunas obras maestras de la literatura brasileña". Ante el estupor que esta declaración debió producir en cualquier escritor brasileño, incluso en cualquier dirigente de las ligas campesinas, claro, Rodríguez Monegal reacciona ridiculizando, no sin cierta mordacidad, una revista que si de algo parecía no carecer, al menos en Francia, era de prestigio. Comenta entonces Rodríguez Monegal: "Escritos, seguramente, con los conocidos seudónimos de Euclides da Cunha (Os Sertões, 1902) o de João Guimarães Rosa (Grande Sertão: Veredas, 1956), a no ser que se trate de las Obras Completas publicadas bajo el nombre literario de Machado de Assis. En serio: Julião no necesita de tales abogados. Su obra política puede defenderse por sí sola" (MN: 2, 66). La crítica a Le Nouvel Observateur se publica en una sección que aparece por primera vez en el segundo número de Mundo Nuevo y que en el futuro aparecerá en pocas ocasiones. "SIC" es su título, y le debe su existencia a los errores garrafales que sobre literatura y escritores de América Latina aparecen en algunas 
revistas, como es el caso de la parisina arriba comentada, lo cual autoriza a su creador a criticar y a corregir, tomando distancia de los que se exponen al ridículo de la falta de rigor profesional, uno de los lemas que marcó su trabajo.

"Sextante", por su lado, actualiza al lector sobre la internacionalización de la novela latinoamericana a través de las traducciones a otras lenguas de las narraciones de Guimarães Rosa (Sagarana, 1937) y las tres primeras novelas del ciclo de la caña de azúcar, escritas por José Lins do Rego: Menino de Engenho (1932), Doidinho (1933) y Bangué (1934), agrupadas bajo el título común de la primera, traducida al inglés como Plantation Boy (MN: 2, 69). También se comenta la censura de libros y filmes existente en el país, así como las relaciones entre la actividad política y la editorial. En el apartado "Editores, políticos y censores" se comenta cómo los dirigentes políticos brasileños, una vez desplazados de sus funciones por la dictadura militar, se dedican a la actividad editorial, como es el caso de Carlos Lacerda, fundador de Nova Fronteira, y Jânio Quadros, que se dedica a la publicación de obras didácticas. Se critica igualmente la actividad censora de la iglesia católica, que había prohibido el largometraje $O$ padre e a moça, de Joaquim Pedro de Andrade (MN: 3, 76-77)

En su primera fase, como se ha dicho, Mundo Nuevo estuvo dedicada a celebrar la nueva narrativa latinoamericana, por lo que el recorte literario se centra básicamente en la narrativa. La muestra de la literatura brasileña es hecha por el propio Rodríguez Monegal, que era uruguayo de padre brasileño, y conocía perfectamente el portugués de Brasil. Básicamente, el recorte que hace se centra en la figura de Guimarães Rosa, a través de la cual se presenta el lado internacional y moderno de la literatura brasileña; el autor de Grande Sertão: Veredas proyecta la imagen del intelectual constructor del nuevo canon literario, que por su carrera diplomática espejea cierto refinamiento, ya codificado como valor simbólico, a la vez que universaliza lo local, estilísticamente rebajado por el realismo social.

Así, la presencia de la literatura brasileña en Mundo Nuevo responde a uno de los objetivos esenciales de Rodríguez Monegal: acabar con "los cotos", con los nacionalismos y los provincianismos que balcanizaban las letras del continente. Este propósito unificador pretende también mostrar la consolidación y la originalidad de una literatura tradicionalmente vista como marginal desde los centros occidentales hegemónicos. Además de proyectar una imagen predominantemente letrada de América Latina, Rodríguez Monegal reconoce a los países por la calidad de sus colaboraciones, por las figuras que desde el punto de vista estético están construyendo el nuevo canon y cuyos presupuestos comparte. Así, la narrativa brasileña 
que él destaca en su revista es la que trabaja con los valores literarios que tanto él como el resto de los escritores del llamado "boom" reivindican: la superación o el rechazo al realismo y la reivindicación de la libertad estética por sobre el compromiso político, lo cual implica entender la construcción de la nueva literatura como un fenómeno de la lengua y no como un cambio que se desprende de los acontecimientos políticos, tal y como la izquierda latinoamericana comprometida con la Revolución cubana defendía.

\section{Separados por la lengua, unidos por el lenguaje.}

El número 6 de Mundo Nuevo (diciembre de 1966) comienza con un editorial titulado "La otra mitad", donde Rodríguez Monegal trata de acercar, desde el punto de vista de la geografía cultural, a Brasil de América Latina. Si bien el crítico presenta la separación lingüística como una dificultad mal encarada por los intelectuales del área hispánica -a diferencia de los brasileños, en cuyas bibliotecas "no es extraño ver libros en español" (p. 4)-, lo cierto es que el error que Mundo Nuevo trata de corregir en el plano literario acaba manifestándose conceptualmente, al excluir al Brasil del concepto de latinidad. Esa otra mitad "no latina" de la América del Sur es presentada en lo que tiene de semejante con sus contemporáneos de lengua española. Rodríguez Monegal no está interesado en repetir lo poco ya traducido: Graciliano Ramos, Lins do Rêgo y Jorge Amado. Su interés es "reparar una injusticia" (p. 4), y para garantizarlo no encomienda a ningún crítico brasileño la selección de la escueta muestra la cual incluye, además de algunos de los primeros cuentos de Guimarães Rosa, narraciones de Nélida Piñón y la escritura "dura" e "insobornable" de Clarice Lispector. Lo que él denomina una injusticia es el hecho de que, a pesar de Brasil estar experimentando también con el lenguaje de la nueva novela, lo que se conoce de su literatura internacionalmente es apenas el enfoque regionalista: "Aunque este enfoque tiene algún mérito, se basa en algunos presupuestos erróneos. Parece implicar que la novela en Brasil está sólo condicionada por el medio, que sus novelistas están escribiendo sólo dentro de los esquemas del realismo, que la novela en una palabra es una forma documental". (MN: 6, 5)

No obstante, la discusión en torno al realismo, sus modos de lectura crítica, sí aparecen reflejados en la revista. En el número 9 de marzo de 1967 se publica un artículo de Eliane Zagury, también colaboradora de Cadernos Brasileiros, en el cual polemiza de forma velada con el enfoque marxista lukacsiano. En "Graciliano Ramos: un clásico" (MN, 9: 49- 
55), Zagury propone una lectura estética diferente de la sociológica en vigor entre la crítica marxista, argumentando, por medio del análisis estilístico y de las técnicas narrativas, la modernidad estética del clasicismo en las novelas de Graciliano Ramos, São Bernardo, Angústia y Vidas Secas. Primeramente compone un retrato ideoestético del novelista, en el cual aparece como víctima de los defensores del realismo, que realizan lecturas maniqueas de su obra y, al mismo tiempo, como defensor de la independencia del escritor frente a la crítica y las escuelas literarias: "No fue un hombre de profesiones de fe literaria, grupos o escuelas. Nunca renegó de la necesaria soledad e independencia del artista para componer una obra genuina. De ahí la notable diversidad técnica de su obra, que presenta no obstante una unidad muy sólida" (MN, 9: 49). Frente a las expectativas que genera la colectividad, la soledad se erige como símbolo de independencia, y esta última, a su vez, funciona como requisito indispensable para la producción de una obra "genuina". Por otro lado, la "diversidad técnica" de Ramos es presentada como la consecuencia directa de esa libertad creadora.

Del mismo modo que Casa de las Américas erige la defensa de la revolución en valor literario, para Mundo Nuevo el contenido de ese valor está formado por la manera en que Ramos presenta y resuelve el problema de la expresión, o sea, en sus rasgos técnicos y de estilo.

El artículo de Zagury expone, entre otras cuestiones, una forma de leer el realismo diferente de la realizada por la crítica marxista, la cual, sin embargo, le sirve de punto de partida para desarrollar su análisis del lenguaje en las tres novelas. Existe un interés explicito de la revista en soslayar la discusión ideológica sobre el realismo, pero sin dejar de manifestarse al respecto. De hecho, los párrafos introductorios y conclusivos anuncian un posicionamiento estético alternativo, ante la interpretación sociológica que hace Carlos Nelson Coutinho en su texto "Uma Análise Estructural dos Romances de Graciliano Ramos",22:

Establecida así la premisa de que el problema expresivo del personaje es lo que va a crear la estructura formal de la novela de Graciliano Ramos (así como la tipificación social es la que crea la configuración del personaje, como observó Carlos Nelson Coutinho en el artículo antes mencionado), podemos llegar a un concepto del clasicismo estilístico en el autor, teniendo en cuenta principalmente esa misma diversidad de estructura y lenguaje de las tres novelas (MN, 9, 51).

Este contrapunteo con la crítica marxista marca también las tensiones por la apropiación del legado estético del autor de Vidas Secas. Para Coutinho, los valores literarios

\footnotetext{
${ }^{22}$ Revista Civilização Brasileira, ${ }^{\text {a }}$ 1, n. 5-6, marzo de 1966.
} 
de la obras de Ramos provienen de su lectura del contexto social, mientras que Zagury defiende la idea de que la literatura debe ser estudiada en planos que recojan, a través de la sustancia lingüística, sus vínculos con diferentes versiones de lo real, en lugar de reducirlas a la relación causal entre obra y contexto.

La perspectiva adoptada por Rodríguez Monegal es la que analiza la literatura fuera de los moldes del realismo, la que muestra el cambio de la norma literaria y coloca al Brasil en una relación de igualdad con las letras hispanoamericanas. En la valoración con que el director de Mundo Nuevo introduce los textos brasileños muestra cómo lo que él llama "dicción nacional” (p. 5), esto es, el enfoque regionalista, termina convirtiéndose en un "callejón sin salida" (p. 6) para la literatura brasileña, por la manera superficial con que se trata el lenguaje, y por sus vínculos estrechos con el realismo que no experimenta, que no es creador. Guimarães Rosa aparece entonces como el escritor que cambia la naturaleza del enfoque de la realidad, por la diferencia de profundidad que existe en su obra, independientemente del tema, que continúa siendo regionalista. Para Rodríguez Monegal, la profundidad de la obra del autor de Grande Sertão: Veredas está dada por el dominio de las técnicas narrativas, en especial del monólogo, a través del cual el protagonista "crea un mundo" (p. 9); también, por la maestría con que este autor supera lo que él denomina "las trampas del realismo".

Otro elemento interesante levantado por Rodríguez Monegal es mostrar que las influencias literarias tanto de Guimarães Rosa como de los escritores hispanoamericanos del Boom -la novela experimental europea y la moderna narrativa norteamericana de la primera mitad del siglo XX- acaban determinando sus confluencias en una misma corriente literaria de carácter paranacional. Menciona, por ejemplo, las semejanzas entre Grande Sertão: Veredas y La casa verde, de Mario Vargas Llosa, mientras que en el plano del lenguaje acerca la obra de Guimarães Rosa de la de James Joyce, ya que ambos magnifican mundos esencialmente verbales. Pero lo que según el crítico uruguayo diferencia a Guimarães del resto de los novelistas brasileños es la sutilidad con que en su obra cruzó la línea que separa lo regional de lo universal. Una crónica y fragmentos de trabajos ya publicados sobre la figura y la obra de Guimarães Rosa aparecerán nuevamente en la revista, a propósito de su muerte, acompañados de otros dos relatos de Primeras historias: "Ninguno, ninguna" y "El caballo que bebía cerveza" (MN: 20, 17-24). 
Además de presentar a quien él considera la gran figura de las letras brasileñas, Rodríguez Monegal introduce al grupo de escritores vinculados al llamado Novo Romance Brasileiro, en cuya denominación se reconoce la influencia del nouveau roman. Dentro de este grupo distingue a los que adaptan "ingeniosamente" esta corriente literaria francesa de los que constituyen "realmente" un nuevo movimiento. Clarice Lispector se erige en "el maestro aceptado de la novela experimental de los años sesenta", apenas comparable a Virginia Woolf. Según Rodríguez Monegal, para leer a Lispector se necesita de un "gusto adquirido", mientras que la narrativa de Guimarães Rosa aparece como más atractiva por ser más universal. Sin embargo, lo que al crítico le interesa destacar en ambos es "la importancia del lenguaje creador en la novela". Al ubicarlos dentro del contexto latinoamericano, Lispector y Guimarães Rosa se erigen en los representantes visibles de determinados estilos literarios en las letras brasileñas, que entroncan con idénticos rasgos, igualmente visibles en la ficción hispanoamericana de los años sesenta.

La presencia de estos escritores en las páginas de Mundo Nuevo sirve no sólo para ilustrar la expansión y hegemonía de cierto modelo literario, sino también su función legitimante ante el poderío de los enunciados políticos que circulaban y controlaban el discurso de los intelectuales de izquierda comprometidos con la Revolución cubana, con las guerrillas y con las luchas de las minorías. Para Rodríguez Monegal, son estos los escritores que permitieron tomar conciencia "de que el realismo documental (o socialista, como también se le llama) está liquidado; que el regionalismo como mera expresión del color local está muerto; que el verdadero y único compromiso del novelista como tal es con su visión personal del mundo y con su arte" (MN: 6,13).

Podría afirmarse, pues, que Mundo Nuevo se constituye, desde el punto de vista teórico, en acta de defunción del realismo social, y que es en función de ese interés renovador del canon literario que incluye o excluye autores y obras. Podría afirmarse también que se trata de un interés personal de su director, cuya libertad para preparar cada número de la revista le había sido garantizada por su agente financiador. Sin embargo, esto no significa que Mundo Nuevo se haya visto totalmente libre de los compromisos institucionales.

A este panorama equilibrado y compacto de las letras brasileñas, en el que predomina el criterio de la renovación estética, se le suma como nota disonante una reseña de Luro Bro sobre el periodista, novelista y autor teatral Guilherme Figueiredo. Esto, ya en el número 4 de la revista, o sea, dos números antes de presentar a la "nueva narrativa brasileña". Esto se 
explicaría únicamente desde el punto de vista institucional, ya que Figueiredo era en aquel momento Agregado Cultural en París de la Embajada brasileña, esto es, representante oficial del gobierno militar, con cuyo cargo jamás habría conseguido publicar una sola línea en las revistas latino-americanas más activas del momento, como Casa de las Américas (Cuba), Marcha (Uruguay) o La Rosa Blindada (Argentina), que eran rigurosamente controladas por los intelectuales de izquierda en guerra declarada contra el liberalismo. A través del texto de Luro Bro, Mundo Nuevo muestra la otra cara de la moneda que completa el capital intelectual del continente. Muestra, y ése es uno de los grandes empeños de Rodríguez Monegal, que los valores artísticos y literarios ocupan la primera posición en la escala de las prioridades del escritor. De cualquier manera, la figura de Guilherme Figueiredo y la repercusión que según Mundo Nuevo tuvo en Europa su obra teatral La zorra y las uvas, se encuentran bastante distantes del modelo estético que el crítico uruguayo se había empeñado en promover. Para el reseñista, la clave del éxito de este autor brasileño reside en "los valores puramente teatrales que encierra" y en "la frescura de un mensaje humano no comprometido que permite a cada auditorio interpretarla en relación con los problemas más candentes de cada país" (MN: 4, 73). Así, la presencia de Guilherme Figueiredo en las páginas de la gran promotora del "boom" de la novela podría ser interpretada como una estrategia institucional con el objetivo de mantener en circulación autores y obras cuyos enunciados ideológicos promuevan una imagen aséptica del intelectual liberal.

\section{El Concretismo: ese ausente presente}

Una ausencia llama poderosamente la atención en la primera etapa de Mundo Nuevo: si bien publica selecciones de la joven poesía de algunos países hispanoamericanos, la brasileña, tradicionalmente reconocida por sus nombres ilustres -Drummond, Bandeira- y aclamada bajo el impacto del Concretismo brilla por su ausencia. Aventurar la hipótesis de que esta omisión estaría justificada por el gusto y la formación literaria del primer director de Mundo Nuevo no se sustentaría, si pensamos en el impulso que la revista dio al uso experimental del lenguaje. Sería interesante investigar si a mediados de los años sesenta el grupo de poetas concretistas de São Paulo había conquistado plaza en los círculos intelectuales de Rio de Janeiro, donde Rodríguez Monegal tenía más contacto, y si, por otro lado, estos poetas concretistas estaban interesados o no, por sus filiaciones ideológicas, en 
colaborar con una revista liberal. Lo cierto es que, más allá del objetivo central de Mundo Nuevo (promover la "nueva novela" latinoamericana), tampoco se puede afirmar que las colaboraciones de poesía que aparecieron en la revista fueron accidentales. Por su presentación y organicidad se puede observar que se trata de colaboraciones encomendadas y rigurosamente escogidas. Pero en el caso brasileño, apenas una antología de poesía es reseñada en apenas veinte líneas; se trata de la Antología da Moderna Poesia Brasileira, publicada en Rio de Janeiro por las Ediciones Orfeo (MN: 17, 89).

Si bien bajo la dirección de Horacio Daniel Rodríguez Mundo Nuevo da prioridad al enfoque sociológico y desvía su atención hacia temas esencialmente históricos y políticos, la literatura $-\mathrm{y}$ la cultura brasileña en general- aparece recogida bajo una perspectiva absolutamente panorámica; se trata de valoraciones generales presentadas a un público hispanoamericano según los ultrapasados métodos de análisis estilístico, justo en un momento en que los análisis estructuralistas presentaban nuevas interpretaciones de géneros y discursos. En casi todos los artículos se trata de resaltar los elementos nacionales que definen la originalidad del arte y la literatura de Brasil. Generalmente el recorrido histórico se justifica como soporte para la presentación de las más recientes manifestaciones artísticas que signifiquen renovación, apertura, contemporaneidad.

Aparecen entonces algunas colaboraciones sobre poesía, literatura y teatro: el profesor Afrânio Coutinho escribe sobre el "Espíritu nacional en la crítica brasileña" (MN: 28, 54-64), que contiene un enfoque analítico bien diferente del que Mundo Nuevo promoviera durante la dirección de Rodríguez Monegal. Coutinho trata de mostrar el desarrollo progresivo alcanzado por el sentimiento de nacionalidad en la producción literaria brasileña, desde el período barroco hasta el Modernismo, poniendo de relieve lo nacional y lo regional como elementos de integración a lo universal. El enfoque histórico de Coutinho tiende a resaltar los valores culturales brasileños, pero los limita en su interacción con la cultura universal vista como museo, por lo que su interpretación de la cultura brasileña, diferentemente de Rodríguez Monegal, se detiene más en el efecto acumulativo del desarrollo histórico, que en las rupturas de la contemporaneidad.

En ese mismo número, el periodista y poeta Walmir Ayala publica, en un estilo más vigoroso y despojado, una valoración bastante personal aunque igualmente periodizadora y panorámica, que llega hasta "La novísima generación de poetas brasileños" (MN, 28: 65-69). Ayala, que se agrupa junto a los poetas concretistas , apenas comenta cuál había sido hasta ese 
momento la presencia del Concretismo tanto en Brasil como en el exterior. Su artículo enfoca a esta "novísima generación" como "un coro" y critica a la del 45 como la hacedora de una " pésima poesía política, llorona y grandilocuente, queriendo romper banderas a golpes de navajas de oro", con la excepción de João Cabral de Melo Neto. De esta manera, la presencia del movimiento concretista se hace aún más notable por su ausencia, y se alza solitaria entre generaciones cuyos defectos no rebasan las propias circunstancias en que surgieron. Para Ayala, el Concretismo realiza contribuciones formales que lo legitiman como movimiento y como expresión de una poesía revolucionaria, "por la estructura del poema, por la abolición del verso, por la valorización del espacio gráfico, por la investigación de la esencia de la palabra, de la reinvención del mundo poético a partir de cero" (MN: 28, 66). Por otro lado, no realiza ninguna crítica a los poetas concretistas, con lo cual autoriza a su grupo como el único original, que consiguió renovar el lenguaje poético sin necesariamente tener que someterlo a otros lenguajes, como el de la política o del discurso social.

Su artículo puede considerarse también como una denuncia de la elitización de la crítica canónica, que solamente se ocupaba de figuras consagradas, como Camões y Machado de Assis, olvidando la intervención de las expresiones artísticas experimentales de esas últimas décadas. A pesar de publicar este artículo con el interés manifiesto de promover el trabajo de los jóvenes poetas brasileños, al tiempo que los sitúa como continuadores del Concretismo, muestra también su lado empobrecedor: "Hasta hoy, imposibilitados de un lenguaje discursivo que refleje su rebelión, apelan a esta reclusión amarga de lidiar con las palabras, cosificándolas, dinamitándolas en el verso para arrojar (según dicen ellos) la joya de su verdad. A mi ver, lo que hacen es empobrecer más su poesía” (MN:28, 66).

Para justificar su afirmación sobre la inexistencia de voces disonantes en el coro de los novísimos, este periodista, crítico y poeta toma algunos ejemplos "al azar", como "indicios de caminos y de aprendizaje técnicos alcanzados por una generación que vio pasar muchas cosas desde el nacimiento de nuestro modernismo" (MN: 28, 67). Bajo este criterio, azaroso y amargo sobre la poesía predominantemente rebelde y social, pero nada creativa en sus rasgos formales, Walmir Ayala escoge para su selección (bilingüe) poemas de Julio Jose de Oliveira, Pedro Lourenço, Fernando Rios y Eduardo Alves da Costa, cuyas obras inútilmente he tentado rastrear en los catálogos de las bibliotecas universitarias de São Paulo. Tal vez el juicio de Ayala no estuviese del todo desacertado. 
Al leer la segunda etapa de Mundo Nuevo, se hace evidente que ante la salida de Rodríguez Monegal la alternativa crítica que la revista encuentra para garantizar la presencia de la cultura brasileña en sus páginas es la que la figura de Afrânio Coutinho le ofrece a través del vínculo institucional con Cadernos Brasileiros. De la fase valorativa la revista transita hacia la fase panorámica, donde la generalización excesiva en el tratamiento de géneros y autores apenas contribuye para promover a la literatura brasileña de los años sesenta por sus valores estrictamente literarios del modo en que lo hizo Rodríguez Monegal. Treinta y cinco números después de Rodríguez Monegal haber presentado su enjundioso artículo sobre la nueva narrativa brasileña, el propio Coutinho apela a la figura de Guimarães Rosa y publica un relato inédito en español, "El Emperador", precedido de un brevísimo análisis del mismo. La traductora, Haydée M. Jofre Barroso, introduce por su lado una nota en la que comenta las singularidades de la lengua empleada por Guimarães, considerándolas la base del criterio de traducción por ella adoptado.

De manera general puede afirmarse que la literatura brasileña no perdió espacio dentro de las páginas de Mundo Nuevo, pero el nuevo giro interpretativo adoptado por su segundo director empobreció la calidad de los trabajos, que en lugar de analizar en profundidad un momento tan fecundo de su literatura, lo diluyó en el diacronismo e hizo caer temporalmente en el olvido el proyecto inicial de la revista.

Para terminar podríamos preguntarnos: del recorte de la literatura brasileña hecho por Casa de las Américas y Mundo Nuevo durante la década del sesenta, ¿qué es lo que ha perdurado? Si bien es cierto que con el paso del tiempo las revistas envejecen, las obras se publican y algunos escritores dejan de producir buenos textos, la muerte o la perennidad de una revista depende en buena medida de su afán totalizador, y de su capacidad de captar en el riesgo de su propia coyuntura los rasgos que modifican, enriquecen e impulsan a la literatura de un país o de todo un continente. De las letras brasileñas, la revista cubana se empeñó en mostrar los vínculos sociohistóricos que esta literatura mantenía con el resto del continente, mientras que Mundo Nuevo se interesó por destacar los elementos que muestran al lenguaje como una estructura universal capaz de rebasar los límites nacionalistas, en un momento en que el mundo se masificaba y la novela hispanoamericana se afincaba en los centros hegemónicos llevando el augurio de grandes bonanzas. 


\section{Bibliografía}

CADERNOS BRASILEIROS. Rio de Janeiro: Associação Brasileira do Congresso pela Liberdade da Cultura, 1959-1970. ISSN 0007-9413.

CASA DE LAS AMÉRICAS. La Habana: Casa de las Américas, 1960. ISSN 0008-7157.

CASAÑAS, I.; FORNET, J. Premio Casa de las Américas. Memoria. La Habana, Fondo Editorial Casa de las Américas, 1999.

NAVARRO, C. P. S. Cronología: 25 años de Revolución. La Habana: Editora Política, 1987.

MONEGAL, E.R. Literatura y Revolución en las letras cubanas. Revista Iberoamericana, University of Pittsburg, v. xli, n. 92-93, jul-dic, 1975.

BERGHE, K.V. Intelectuales y Anticomunismo. La revista 'Cadernos Brasileiros' (19591970). Leuven University Press, 1997.

MUNDO NUEVO. Paris, 1966 - Buenos Aires, 1971.

COUTINHO, C.N. Uma análise estructural dos romances de Graciliano Ramos. Revista Civilização Brasileira, ano 1, n. 5-6, março de 1966. 